\title{
Thoracoabdominal aortic aneurysm repair: current endovascular perspectives
}

\author{
This article was published in the following Dove Press journal: \\ Vascular Health and Risk Management \\ 19 August 2014 \\ Number of times this article has been viewed
}

\section{Nathan Orr \\ David Minion \\ Joseph L Bobadilla \\ Vascular and Endovascular Surgery, Department of Surgery, University of Kentucky, Lexington, KY, USA}

\begin{abstract}
Thoracoabdominal aneurysms account for roughly 3\% of identified aneurysms annually in the United States. Advancements in endovascular techniques and devices have broadened their application to these complex surgical problems. This paper will focus on the current state of endovascular thoracoabdominal aneurysm repair, including specific considerations in patient selection, operative planning, and perioperative complications. Both total endovascular and hybrid options will be considered.
\end{abstract}

Keywords: thoracoabdominal aneurysm, thoracic aorta, TEVAR, endovascular surgery

\section{Introduction}

Aneurysms of the thoracoabdominal aorta (TAAs) are relatively uncommon in the spectrum of aneurysmal disease, accounting for only $3 \%$ of diagnosed aneurysms in the United States (US). ${ }^{1}$ This results in roughly ten new aneurysms per 100,000 personyears. ${ }^{2,3}$ The initial classification schema for TAAs was described in 1986 by Crawford and Coselli. ${ }^{4}$ This included four subtypes of varying extent of the thoracic and abdominal aorta. In 1999 Safi and Miller modified the initial Crawford classification by adding a fifth subtype (Figure 1). ${ }^{5}$ Both female sex and the presence of Chronic Obstructive Pulmonary Disease (COPD) have been associated with increased risk of rupture. While female sex has been associated with delayed time to aneurysm formation, the absolute risk of rupture is increased in size for size match cohorts. COPD has been associated with a 3.6-fold higher risk of rupture. ${ }^{6}$ Longitudinal studies have shown that for every $1 \mathrm{~cm}$ growth over $5 \mathrm{~cm}$, the risk of rupture doubles. ${ }^{6}$ Untreated, nearly $80 \%$ will progress to rupture. ${ }^{7}$ At $6-6.5 \mathrm{~cm}$, that annualized risk of rupture is roughly $7 \%$; as such, this is often the threshold for intervention. ${ }^{8}$

The first published reports of TAA repair were in 1955 by Etheredge et al and Rob. ${ }^{9,10}$ These aneurysms were approached via a left lateral thoracoabdominal incision and included reconstruction of the visceral segment of the abdominal aorta. Two years prior to this, De Bakey and Cooley reported their experience with isolated thoracic aortic aneurysms. ${ }^{11}$ Over the next 10 years, they amassed 42 patients who underwent repair utilizing Dacron interposition grafts. ${ }^{12}$ In 1974, E Stanley Crawford reported his experience with visceral pedicles, including en bloc anastomosis of the celiac, superior mesenteric artery (SMA), and right renal, followed by isolated left renal reimplantation. ${ }^{13}$ Despite improvements in operative technique and anesthetic support, operative mortality after open repair continues to range from $3 \%$ to $8 \%{ }^{14}$ Strategies for aneurysm repair took a drastic deviation with the initial descriptions 


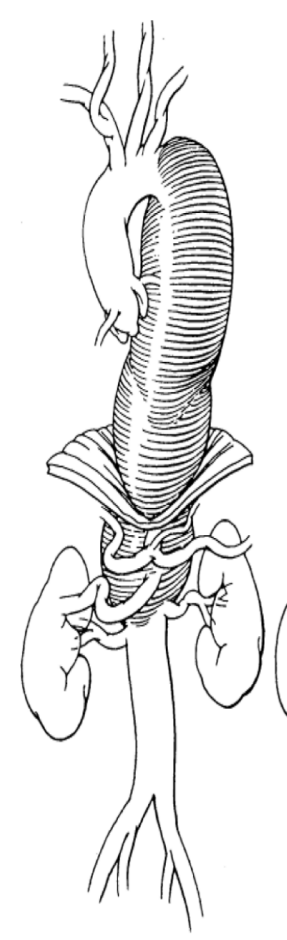

I

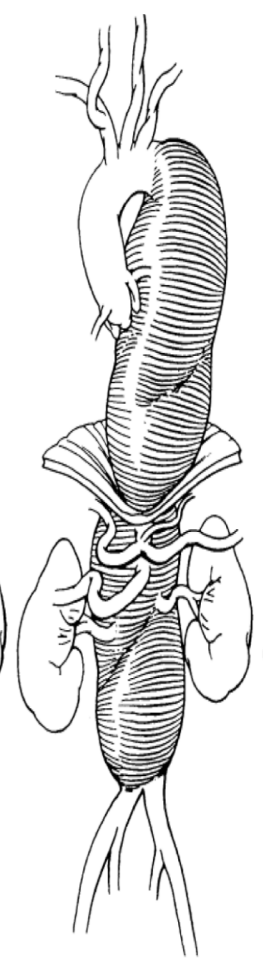

II

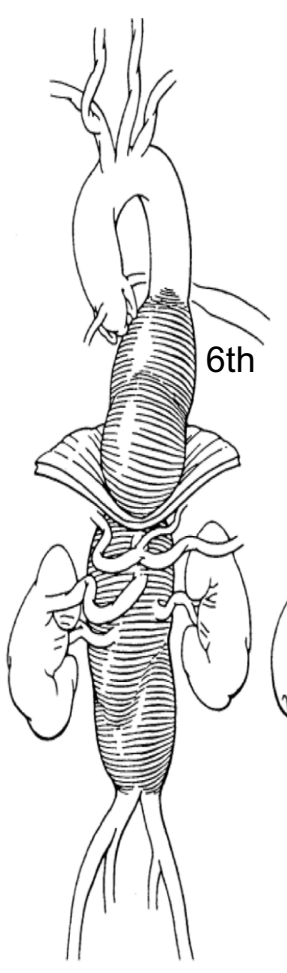

III

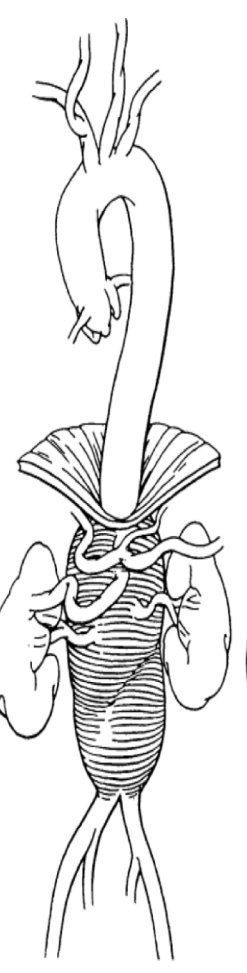

IV

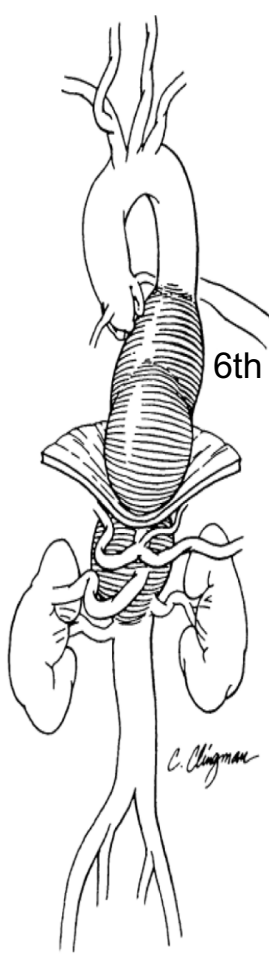

V

Figure I Thoracoabdominal aneurysm classification.

Notes: Type I extends from the left subclavian artery to the celiac axis. Type II extends from the left subclavian artery and includes the infrarenal abdominal aorta to the level of the aortic bifurcation. Type III extends from the sixth intercostal space to the iliac bifurcation. Type IV extends from the visceral abdominal aorta to the iliac bifurcation. Type V extends from the sixth intercostal space to just above the renal arteries. Reprinted from The Annals of Thoracic Surgery, 67(6), Safi HJ, Miller CC 3rd, Spinal cord protection in descending thoracic and thoracoabdominal aortic repair, 1937-1939, Copyright (c) 1999, with permission from Elsevier. ${ }^{5}$

of transfemoral treatment in $1991 .{ }^{15}$ Continued efforts to expand the use of this technology and reduce morbidity and mortality of TAA repair led to the first endovascular exclusion reported in 1994. ${ }^{16}$ The US Food and Drug Administration (FDA) approved the first thoracic endograft in 2005. Current endovascular techniques include debranching procedures whereby proximal or distal landing zones are created by the construction of extra-anatomic bypass to either visceral or arch vessels. ${ }^{17}$ Another common approach includes the utilization of chimneys, or snorkels, to preserve flow to side branch vessels. ${ }^{18}$ Both represent viable options in the absence of more mature endovascular devices. With the recent availability of fenestrated and side branch devices, the envelope of totally endovascular TAA repair has again been pushed. ${ }^{19}$ Unfortunately, many of these devices require custom fabrication, resulting in a delay of many weeks until treatment can be delivered. Ultimately, the total endovascular repair of complex TAAs will depend on the availability of a usable, modular, off-the-shelf device. ${ }^{20}$ In this paper, we will review the current state of endovascular TAA repair technology, including hybrid solutions and total endovascular treatment options for this complex and challenging disease.

\section{Patient selection and evaluation}

Elefteriades and Botta have nicely outlined guidelines for intervention for TAAs in their recent publication (Table 1). ${ }^{21}$ These indications include: 1) rupture, 2) acute dissection, 3) persistent symptomatic state, 4) rapid growth, and 5) absolute size criterion. In the urgent and emergent setting, one does not have the luxury of a complete preoperative evaluation and risk factor management; however, in the elective patients, a standardized work-up for aortic surgery should be completed. This should include pulmonary, cardiac, and renal evaluations. Pre-existing renal insufficiency has been shown to be an independent predictor for postoperative morbidity and mortality in multiple studies. ${ }^{22-24}$ With the added use of nephrotoxic contrast agents essential to endovascular procedures, this common comorbidity becomes even more important. In addition, patients may also undergo spinal magnetic resonance angiography (MRA) to identify important intercostal arteries to attempt to salvage during 
Table I Criteria for thoracoabdominal aneurysm intervention

\begin{tabular}{ll}
\hline Criterion & Specific description \\
\hline Aneurysm rupture & $\begin{array}{l}\text { As identified on radiographic studies or as } \\
\text { clinically apparent }\end{array}$ \\
Acute dissection & $\begin{array}{l}\text { Including ascending aorta or distal aorta with } \\
\text { malperfusion of visceral end organs or lower } \\
\text { extremities }\end{array}$ \\
& $\begin{array}{l}\text { Including localized pain, adjacent organ } \\
\text { compression, and/or aortic valvular insufficiency }\end{array}$ \\
Persistent & Defined as growth $\geq I$ cm/year \\
symptomatic state & Known connective tissue disorder \\
Rapid growth & - Ascending: $>5.0 \mathrm{~cm}$ \\
Absolute size & - Descending: $>6.0 \mathrm{~cm}$ \\
& No known connective tissue disorder \\
& - Ascending: $>5.5 \mathrm{~cm}$ \\
& - Descending: $>6.5 \mathrm{~cm}$
\end{tabular}

Notes: Specific criteria for intervention on thoracoabdominal aneurysms include the major categories of rupture, dissection, symptomatic nature, rapid growth, and standard progressive degenerative dilation. Adapted from Surg Clin North Am, 89(4), Elefteriades JA, Botta DM Jr, Indications for the treatment of thoracic aortic aneurysms, 845-867, Copyright (C) 2009, with permission from Elsevier. ${ }^{21}$

long segment coverage. ${ }^{25}$ If possible, staged repair has been shown to reduce the incidence of postoperative paraplegia, by allowing collateral pathways to the anterior spinal artery to mature during serial interventions. ${ }^{26,27}$ Computed tomographic angiography of the aorta and branch vessels with three-dimensional reconstruction and postprocessing image manipulation software are essential tools when advanced endovascular techniques are being utilized. ${ }^{28}$ True centerline measurements and multiplanar reconstructions are essential in the accurate evaluation and planning, including the evaluation of proximal and distal landing zones, the degree of aortic tortuosity, the relationship of the aneurysm to arch and visceral branch vessels, and the size and quality of the access vessels.

\section{Complications}

Complications associated with thoracoabdominal thoracic endovascular aneurysm repair (TEVAR) include stroke (3\%-5\%), paraplegia (up to $6 \%$ ), access site complications $(6 \%-14 \%)$, endoleaks $(9 \%-38 \%)$, device migration $(0.7 \%-3.9 \%)$, graft collapse (rare), and persistent aneurysm sac enlargement $(7.1 \%-14.5 \%) .{ }^{29-36}$ As teams progress along the learning curve and gain experience with preoperative planning and graft deployment techniques, the rates of these complications tend to diminish.

\section{Renal failure and contrast- induced nephropathy}

A 2006 review of contrast-induced nephropathy (CIN) estimated the risk of CIN to be between $8 \%-14.5 \% .{ }^{37}$ While the risk of CIN is clearly linked to the amount of contrast and pre-existing renal function, there is a very real risk of precipitous renal function decline and potential dialysis in any patient with a multitude of risk factors. These risk factors include diabetes, age over 75 years, periprocedural volume depletion, heart failure, cirrhosis or nephrosis, hypertension, proteinuria, recent use of nonsteroidal anti-inflammatory drugs, and intra-arterial injection of contrast as opposed to intravenous. ${ }^{37,38}$ Many of these risk factors are present in our TEVAR populations. With the increasing complexity of cases treated via endovascular techniques, contrast utilization increases as well. As such, we must employ careful and conscious strategies to decrease the volume of these nephrotoxic agents, both intraoperatively and postoperatively. ${ }^{39}$

\section{Cerebrovascular accidents}

Neurological complications, including stroke and spinal cord ischemia, still remain one of the most dreaded challenges facing thoracic aneurysm repairs regardless of the type of surgical approach. The rate of stroke with thoracic aneurysm repair ranges from $3 \%$ to $5 \% .{ }^{29,30}$ The potential etiologies include instrumentation of the aortic arch leading to embolization or coverage of arch branches critical for cerebral perfusion. A critical knowledge of vertebrolateral dominance is crucial during planning and deployment. Pre-emptive carotid subclavian bypass or transposition may be necessary in a nonemergent situation. ${ }^{40}$ In addition, activated clotting time (ACT) measurements should be taken at baseline and complete anticoagulation should be confirmed before any wire or catheter instrumentation of the aortic arch is attempted.

\section{Paraplegia}

In the FDA stent graft trials, spinal cord ischemia and paraplegia rates were diminished with endovascular repair compared to the open approach with a cumulative advantage of $6 \%$ versus $10 \% .^{33,34,41}$ Despite mild improvement in spinal cord ischemia, most experts recommend the routine use of spinal cord protective techniques for endovascular thoracic aneurysm repairs extending greater than $15 \mathrm{~cm}$ or those within $5 \mathrm{~cm}$ of the celiac axis. We have previously shown that with aggressive protective measures, the incidence of spinal ischemia can approach 1\%. ${ }^{42,43}$ Our paraplegia reduction strategies are multimodal and proactive. Management includes routine spinal fluid drainage (spinal fluid pressure $<6 \mathrm{mmHg}$ during intraoperative aortic occlusion/exclusion), avoidance of hypotension (mean arterial pressure 90-100 mmHg during 
and after reperfusion), and perioperative administration of the excitatory neurotransmitter inhibitor naloxone. Spinal drains are routinely left in place for 48 hours, unless clinical parameters mandate longer drainage intervals. The spinal drains are capped when lower extremity motor function is consistently demonstrated. In addition to the interventions above, systemic steroids are administered shortly after anesthesia induction, and mannitol is given just before endovascular device deployment. The ability to stage repair has also been shown to effectively reduce paraplegia rates, presumably by allowing collateral pathways to mature and augment the spinal perfusion. ${ }^{27}$

\section{Graft collapse}

Graft collapse is perhaps the most catastrophic and potentially lethal endovascular device failure. ${ }^{44}$ Often, this failure can result in rapid and potentially complete thoracic aortic occlusion, and has been associated with acute spinal ischemia, limb malperfusion, and renovisceral malperfusion syndromes. ${ }^{45,46}$ Potential factors contributing to this device failure include small aortic landing zone diameters, aggressive oversizing, small radius curvature of the thoracic aorta, and "bird-beaking" of the proximal seal zone, as often seen in young patients with trauma-related aortic injuries. ${ }^{47-49}$ A recent paper helped to elucidate and quantify the shear forces related to proximal malapposition ("bird-beaking") of endografts, and provide the basis for patient-specific modeling to define at-risk endoprosthesis. ${ }^{50}$ If diagnosed and treated expeditiously, most at risk of collapsed grafts can be treated with high radial force interventions, including Palmaz stent placement. ${ }^{51}$

\section{Access complications}

Bilateral access is usually obtained and often requires a 24-French profile, which equates to at least an $8 \mathrm{~mm}$ access diameter for safe delivery. Attention must be given to significant atherosclerotic narrowing or calcification of the external iliac arteries to prevent damage to the vessel during delivery or removal. An additional option includes a small retroperitoneal cutdown to expose the common iliac artery to create a conduit. Other authors have advocated the use of controlled iliac rupture after the placement of an endoconduit. ${ }^{52}$

\section{Endoleaks}

Endoleaks remain a challenging part of endovascular repair. Since their first descriptions in the late 1990s, the classification remains largely unchanged. ${ }^{53,54}$

- Type Ia: Proximal seal failure.
- Type Ib: Distal seal failure.

- Type II: Retrograde branch vessel filling of sac.

- Type III: Failure of device component seal or graft fabric tears.

- Type IV: Graft porosity failure.

Thoracoabdominal endovascular repair remains a viable option for failed standard infrarenal repair. As Martin et al described, branched and fenestrated devices have a role in salvage of late failure of proximal type Ia endoleaks in infrarenal devices. ${ }^{55}$ As one would imagine, with the increasing number of components required to complete total endovascular thoracoabdominal repairs, the incidence of intercomponent failures increases, leading to higher rates of type III endoleaks. This has been estimated as high as $9.3 \%$ in recent series. ${ }^{56}$ The same group published their "lessons learned" in dealing with these complex secondary interventions, including recommendations for technical changes and planning during the index operation. ${ }^{57}$

\section{Total endovascular repair Standard TEVAR}

The current FDA-approved devices for TEVAR include the TAG graft and C-TAG (WL Gore, Flagstaff, AZ, USA), the Talent device (Medtronic, Santa Rosa, CA, USA), the Bolton Relay thoracic graft (Bolton Medical, Sunrise, FL, USA), and the Cook TX2 (Cook Medical, Bloomington, IN, USA). The proximal and distal landing zones must be accurately measured. Most grafts require $10 \%$ to $20 \%$ oversizing of the seal zone diameter. The distal landing zone is usually smaller than the proximal zone, which often results in the use of multiple grafts to adjust for this size difference or the use of a tapered graft. The tendency of the stent graft to follow the greater curvature of the aorta and the natural tortuosity of the vessel often leads to an underestimation of the coverage length. It is important to consider these factors when measuring and planning deployment. Occasionally, Zone 2 or even more proximal landing zones are needed to accomplish adequate seal (Figure 2). Debranching procedures are discussed in detail in the Hybrid Repair Section of this text.

It is generally recommended to have at least $2 \mathrm{~cm}$ of seal zone at either end of the graft to prevent migration. If there is severe angulation, calcification, or thrombus, the seal zone length may need to be extended. Accurate deployment positioning can be improved by performing aortography at an oblique projection of 40 to 60 degrees. Additionally, it is important to apply constant forward pressure during deployment to allow the graft to conform along the outer curvature of the aorta and prevent graft jump. Completion 


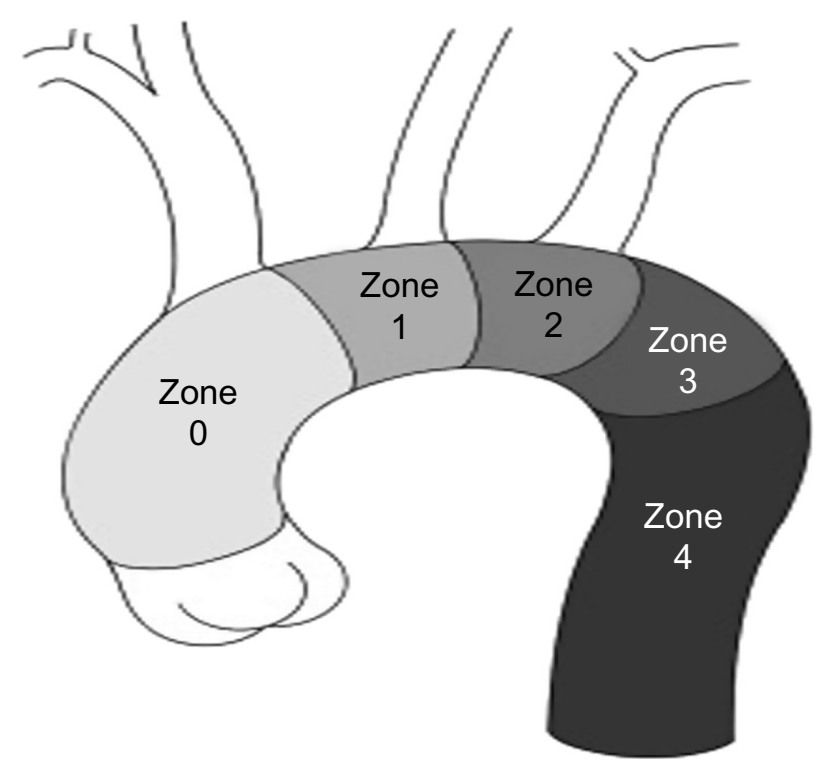

Figure 2 Zones of the aortic arch.

Notes: Proximal landing zone attachment sites for endovascular graft deployment. Reprinted from Surg Clin North Am, 89(4), Adams JD, Garcia LM, Kern JA, Endovascular repair of the thoracic aorta, 895-912, Copyright (c) 2009, with permission from Elsevier. ${ }^{93}$

aortography will confirm exclusion of the aneurysm and allow evaluation for endoleak (Figure 3).

The combined EUROSTAR and UK thoracic endograft registries, which included 249 patients with degenerative aneurysm, found that the 30-day mortality for elective TEVAR was 5.3\%. ${ }^{31}$ The US multicenter trials also showed a significant improvement in mortality with endovascular repair at $2 \%$ versus $6 \%$ for open repair. ${ }^{32}$ Additional studies comparing elective endovascular versus open repairs have found overall mortality rates that were higher than those reported in the multicenter trials, yet still favored the endovascular approach. ${ }^{58,59}$ In terms of ruptured descending thoracic aneurysms (DTAs), multiple meta-analysis found improved mortality with endovascular repair ranging from 19\% for TEVAR versus 33\% for emergent open repair. ${ }^{58,60,61}$

\section{Branched endografts}

Total endovascular repair of thoracoabdominal aortic aneurysms requires a strategy for preservation of any involved branched vessels, specifically the reno-visceral branches. For the most part, strategies have focused on creating a branched configuration in the endograft (Figure 4). One method to create branch points in an endograft is to use a combination of reinforced fenestrations and balloon-expandable covered stents. The proximal end of the covered stent is then flared at the site of the reinforced fenestrations to create a gasket seal. Another method is to use dedicated side branches incorporated into the endograft itself. The dedicated side

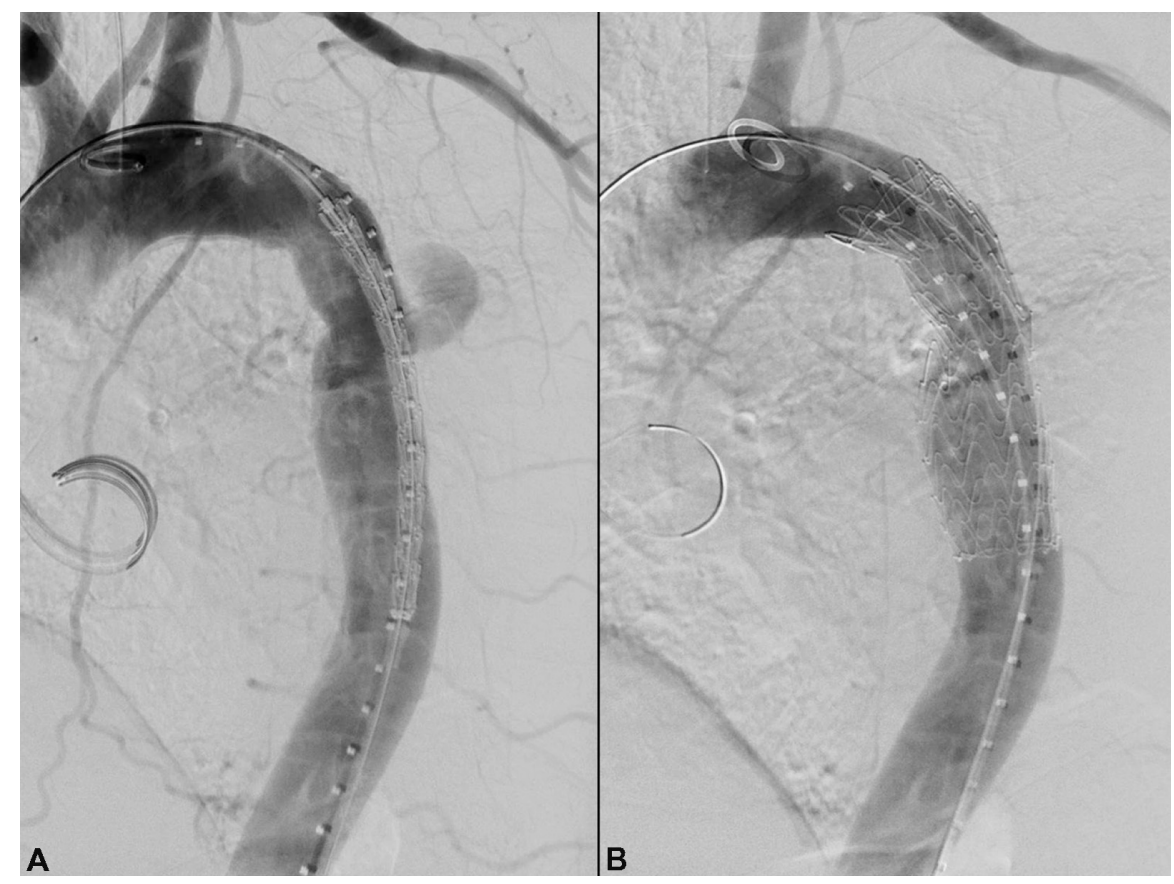

Figure 3 Salvage TEVAR.

Notes: Salvage of failing prior open aortic transection repair using standard TEVAR technique. This 62-year-old patient had had a previous open aortic transection repair at the age of 18 years after a motor vehicle crash. Nearly 45 years later, he presented with acute onset left sided chest and back pain. On CTA he was found to have a pseudoaneurysmal contained leak at his previous anastomotic suture line (A).A single TEVAR device was deployed to cover the suture line pseudoaneurysm (B). His pain resolved and is event free 2 years later.

Abbreviations: TEVAR, thoracic endovascular aneurysm repair; CTA, computed tomographic angiography. 
A

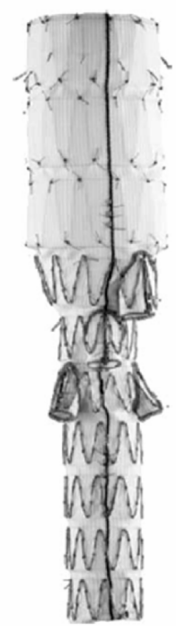

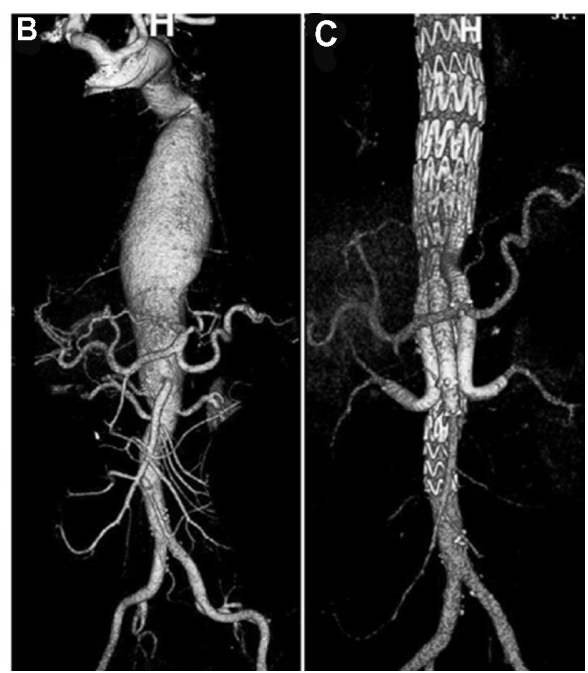

Figure 4 Branched endovascular devices.

Notes: The Zenith t-Branch device (A) (Cook Medical, Bloomington, IN, USA) is designed with four downward projecting branched access limbs. It deploys via a preloaded 22-F delivery system. The superior mesenteric artery branch limb measures $8 \mathrm{~mm}$ wide by $18 \mathrm{~mm}$ long, and the celiac artery branch measures $8 \mathrm{~mm}$ wide by $21 \mathrm{~mm}$ long. The renal side branches measure $6 \mathrm{~mm}$ wide by $18 \mathrm{~mm}$ long. Above is an example of a complex aneurysm both before (B) and after $(\mathbf{C}) \mathrm{t}-\mathrm{Branch}$ endovascular treatment. Copyright @ 2013 International Society of Endovascular Specialists. Reproduced from Bosiers MJ, Bisdas T, Donas KP, Torsello G, Austermann M. Early experience with the first commercially available off-the-shelf multibranched endograft (t-branch) in the treatment of thoracoabdominal aortic aneurysms. J Endovasc Ther. 20I3;20(6):7I9-725. ${ }^{65}$

branches are usually extended into the target vessels using self-expandable covered stents, which themselves are often reinforced with a bare stent to prevent kinking.

Greenberg et al reported on their experience using various combinations of these two approaches in 406 patients with thoracoabdominal aneurysms, as well as 227 patients with juxtarenal aneurysms. ${ }^{62}$ Reinforced fenestrations were the preferred method for renal branches given the angulation of these branches in reference to the aortic centerline. They were also the preferred method for visceral branch preservation in type IV thoracoabdominal aneurysms. Dedicated side branches were used for visceral preservation in type II and III aneurysms if the lumen of the aorta was greater than $35 \mathrm{~mm}$ in diameter at the visceral level and no dissection was present.

In this series, perioperative mortality was $1.8 \%$ for juxtarenal aneurysms, $2.3 \%$ for type IV aneurysms, 5.2\% for type II and III aneurysms, and $12.5 \%$ for type I aneurysms. Late complications included rupture in five patients. In addition, branch vessel occlusion was seen in $2.3 \%$ of reinforced fenestrations at 15 months follow-up and in one side-arm branch. Postoperative sac behavior and endoleak rates were not reported.

In another large series by Haulon's group, 89 patients with TAAs were treated using an endovascular approach similar to Greenberg's. ${ }^{63}$ The TAAs were classified as type I in four patients, type II in 15 patients, type III in 25 patients, and type IV in 45 patients. To this series, reinforced fenestrations were used for 123 renal arteries, 54 superior mesenteric arteries, and 15 celiac arteries. Dedicated side branches were used for 40 renal arteries, 33 superior mesenteric arteries, and 29 celiac arteries.

Technical success was achieved in $96.6 \%$ of the cases. The failures were related to target vessel loss in three patients. Two of these three patients had target vessel loss in more than one vessel, bringing the total to five target vessels. Perioperative mortality was $8.9 \%$. There were no late ruptures in this cohort. At a median follow-up of 17 months, 22 endoleaks were identified (three type III and 19 type II). Sac behavior was not reported.

One of the disadvantages of this approach is the need for custom-designed grafts for each patient. Not only is the commercial availability of these devices limited, but the time frame for manufacturing these devices is generally considered to be in the range of 6 to 8 weeks, which precludes urgent or emergent cases. The t-Branch device (Cook Medical) was released to parts of the world in 2012 as a potential off-the-shelf design utilizing four downward-oriented renovisceral side branches. However, feasibility studies have suggested that this device can still only be used to treat between $63 \%$ to $83 \%$ of cases of thoracoabdominal aneurysms, even when combined with adjuvant procedures such as carotid-subclavian bypass or additional thoracic endografting. ${ }^{20,64}$ Regardless, Bosiers et al reported uniformally excellent results in their early experience of 15 patients treated with this device. ${ }^{65}$

Surgeon-modified devices have been proposed as an alternative to commercially designed devices to further 
increase patient applicability without undue manufacturing delay. However, the reported experience with these techniques is quite limited at present. Ricotta et al reported their experience with surgeon-modified endografts in a cohort that included eight thoracoabdominal aneurysms. ${ }^{66}$ Reinforced fenestrations were used for all branches. There was one perioperative death in the group secondary to subarachnoid hemorrhage and one type III endoleak that required early reintervention. At mean follow-up of 9 months, no other type I or III endoleaks were observed. There was one type II endoleak. There were no cases of postoperative rupture or significant sac growth. Sac regression was observed in 64\% of the total cohort. In a case report, Oderich et al recently described the technique of minicuff reinforced fenestrations using 3-5 mm lengths of smaller stent grafts to create something more akin to a dedicated side branch. ${ }^{67}$ The authors recommend this modification for TAAs with a larger luminal diameter in the visceral segment, specifically those in which the gap between the aortic endograft and the aortic wall is greater than $10 \mathrm{~mm}$.

While these reports certainly attest to the feasibility of surgeon-modified branched grafts, the device planning and technical expertise for success in these cases should not be underestimated. Further, the effect of such modifications on the integrity of the parent device is unknown. Finally, depending on the locality, there are often medicolegal regulations for physician-modified devices that need to be addressed by the sponsoring institution prior to undertaking such a program.

\section{Parallel and molded parallel endografts}

Another popular option for branch vessel preservation during complex aneurysm repair is to use parallel endografts (Figure 5). Two recent publications summarized early results with parallel endografts. ${ }^{18,68}$ These papers included mostly juxtarenal pathologies, but did demonstrate a technical success rate of $98.9 \% .{ }^{68}$ Additionally, they found a $97.8 \%$ patency rate at a mean follow-up interval of 9 months. ${ }^{18}$ While these techniques have been more commonly used for juxtarenal pathologies (ie, the so-called "chimney" or "snorkel" technique), the concept can be applied to TAAs by utilizing a standard endograft as the landing zone for the parallel endografts. This configuration has been referred to as the "sandwich" technique. The technique has been championed by Lobato and Camacho-Lobato, who recently reported a very large series of such cases that included 13 elective and two emergent TAA repairs. ${ }^{69}$ One of the elective thoracoabdominal cases was aborted when neither renal artery could be cannulated. In the remaining 14 cases, a

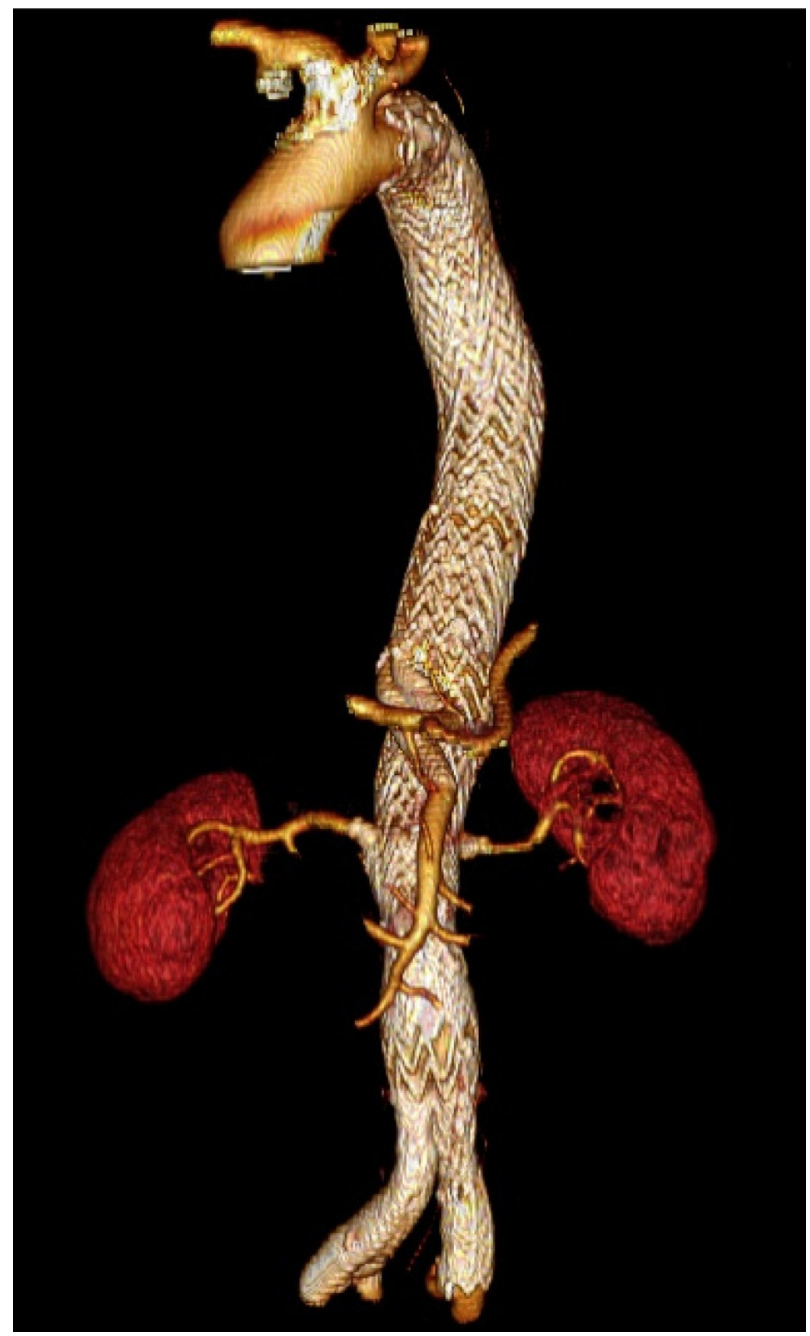

Figure 5 Parallel endografts.

Notes: Postoperative three-dimensional volume rendering of a type II thoracoabdominal aneurysm treated with parallel endografts. The visceral stents were placed antegrade via left axillary access. The renal stents were placed retrograde via contralateral femoral access.

total of five target vessels were sacrificed for various reasons, while 43 were successfully preserved. Perioperative mortality was $8 \%$ in the elective group, with the one death related to hepatic failure in a patient whose celiac artery was intentionally occluded after performing a viability test. The two emergent repairs were performed for rupture and both died in the postoperative period from colonic infarction. One was secondary to an intraoperative SMA dissection and subsequent occlusion, while the other was apparently from hemodynamic instability. At mean follow-up of 16 months, there were no late target vessel losses. Intraoperatively, there was one type I and two type III endoleaks. However, they subsequently resolved. There was no late postoperative rupture or sac growth. Significant sac reduction was observed in all patients who had been followed for at least 24 months. 
While these results are far from perfect, they are comparable to what has been reported for more conventional branched configurations. Unfortunately, the small numbers preclude direct comparison between the two techniques. However, there are theoretical advantages and disadvantages that deserve consideration. The big advantage of parallel endografts is that they are completely modular, providing an off-the-shelf option for almost any anatomy without the need for device modification.

Another advantage is that the branch vessels are cannulated prior to deployment of the aortic endoprosthesis. This advantage can be quite important in three situations. The first is in tortuous anatomy, where alignment of a fenestration or side branch to the target vessel can be very difficult. The second is in small lumens, such as dissections, in which the aortic device may remain partially compressed. The third is when there is significant thrombus in the paravisceral aorta, placing the patient at risk for atheroembolization during deployment of the aortic endoprosthesis. It should be noted that at least one quarter of the perioperative deaths in Haulon's series ${ }^{63}$ of conventional branched grafts were from this etiology. In theory, these deaths may have been prevented if parallel endografts had been used and the renovisceral-covered stents deployed prior to the aortic endoprosthesis.

This distinction is a two-edged sword, though, because one of the disadvantages of parallel endografts is that all branch vessels must be cannulated prior to the aortic endoprosthesis. This requirement poses some logistical issues in terms of access. While Lobato described using bilateral axillobrachial access to accommodate the four renovisceral sheaths, our preference has been to use retrograde-covered stents in the renal arteries placed from sheaths in the contralateral groin and unilateral (left) axillobrachial access for the sheaths used for the visceral stents.

The big disadvantage of parallel endografts, however, is the imperfect seal inherent to the technique. The side-by-side configuration leads to gutters along the parallel endografts, which can result in endoleaks and continued pressurization of the sac.

Many will contend that the gutters can be eliminated by oversizing the aortic stent so that it wraps around the branch stent. In reality, though, endografts are simply not designed to deploy in such a manner. Further, the effect of postballooning is to make the devices more round. In vitro studies have shown that $40 \%$ oversizing of the aortic stent can best minimize (but still does not eliminate) the gutters along a single parallel branch stent. However, this approach also led to significant infolding, leaving the authors to recommend
$30 \%$ oversizing and accepting larger gutters. ${ }^{70}$ Using this amount of oversizing without achieving the prime objective is just not a practical strategy, let alone a feasible one, in larger aortas with multiple parallel endografts.

Alternatively, Lobato has suggested overlap lengths of at least $5 \mathrm{~cm}$ to induce thrombosis of the gutters. In our personal experience, though, we have seen persistent endoleaks with even $10 \mathrm{~cm}$ of overlap. Further, longer overlap lengths may affect patency rates and sometimes necessitate sacrifice of additional lumbar or intercostal vessels.

Our contention is that the gutters can be eliminated by molding the parallel graft into an eye-shape (as opposed to leaving it a round shape) so that the aortic graft can more easily conform to its exposed perimeter. ${ }^{71}$ We refer to this maneuver as the "eye of the tiger" technique (Figure 6).

For the "eye of the tiger" method, a balloon-expandable covered stent (iCAST; Atrium Medical Corporation, NH, USA) is deployed in the target branch vessel alongside a standard aortic endograft. The parallel portion of the iCAST is then postdilated by a factor of approximately 1.6 and the balloon is exchanged back for the original sized balloon. The iCAST is then crushed using a seating balloon in the aortic endograft to establish complete apposition of all perimeters. The central portion of the iCAST is then reinflated with the original sized balloon, creating an eye shape. Kissing balloon angioplasty at low inflation pressures ( 2 atm) then completes the molding. The target length of overlap should be at least as much as that recommended for overlapping aortic devices.

Once the branch stent is molded into an eye-shape, it creates a luminal irregularity resembling that of a perfectly smooth atherosclerotic plaque, which is a shape that aortic endografts are much better designed to conform to.

In addition, the eye shape essentially represents two arcs intersecting at acute angles. The geometric term for this shape is a lens. If a lens is perfectly symmetrical, then by definition the two arcs are of equal length and radius. Therefore, the arc that the aortic endograft must conform to is exactly the same length as the arc that it would have had to conform to if the eye-shaped stent was not present. The only difference is that the arc is now convex rather than concave. The implication of this symmetry is that no additional oversizing of the aortic endograft is necessary. However, since symmetry is not always achieved, some oversizing is recommended.

Finally, it is important to note that we, like many others, have found that a seal can often be achieved with standard tube-shaped parallel endografts, especially when there is minimal potential outflow for any gutter leak. In these cases, we 


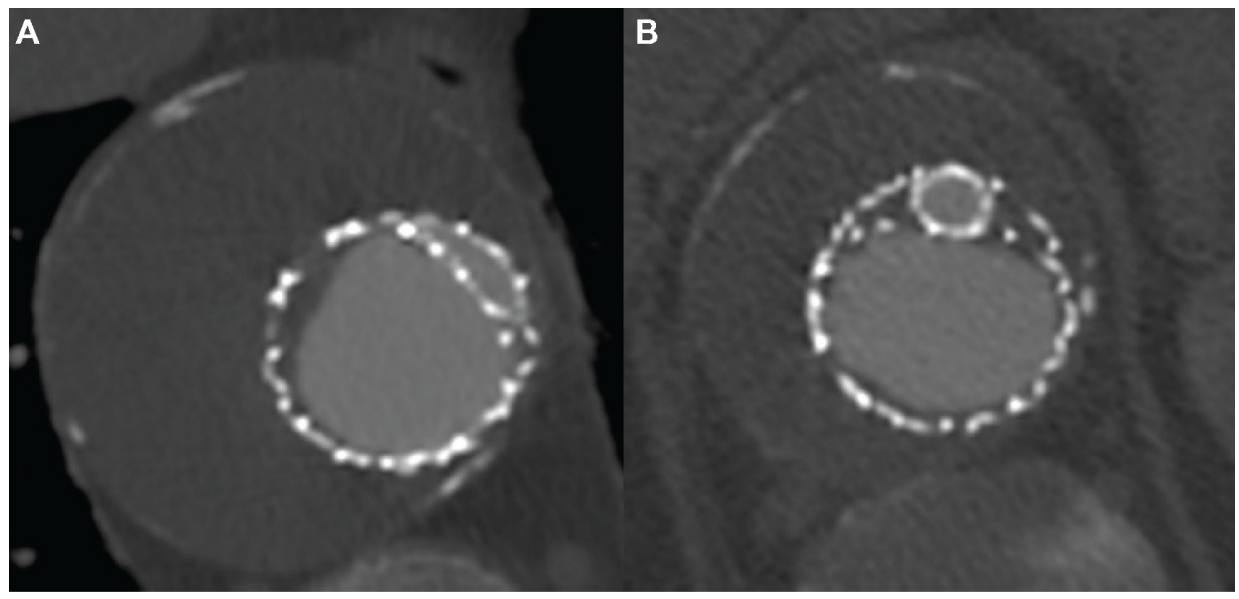

Figure 6 Molded TEVAR.

Notes: Postoperative computed tomography scan of a type $V$ thoracoabdominal aneurysm treated with a single parallel graft to the celiac artery. The parallel graft has been molded to an eye-shape more proximally in the overlap zone to allow for perfect apposition of the multiple endoprostheses and elimination of any potential gutters (A). The parallel graft remains round more distally in the overlap zone near the origin of the celiac artery. Note the large gutters (B) that would have likely resulted in an endoleak if this covered stent had not been molded to an eye-shape more proximally.

Abbreviation: TEVAR, thoracic endovascular aneurysm repair.

usually test the waters with a standard parallel configuration, then only proceed with the "eye of the tiger" maneuver if there is persistent intraoperative type III endoleak.

\section{Hybrid repair}

The hybrid technique involves extra-anatomic debranching combined with staged or immediate endovascular aortic relining using covered aortic stent grafts (Figure 7). This combined approach was first performed in 1999 by Quiñones-Baldrich

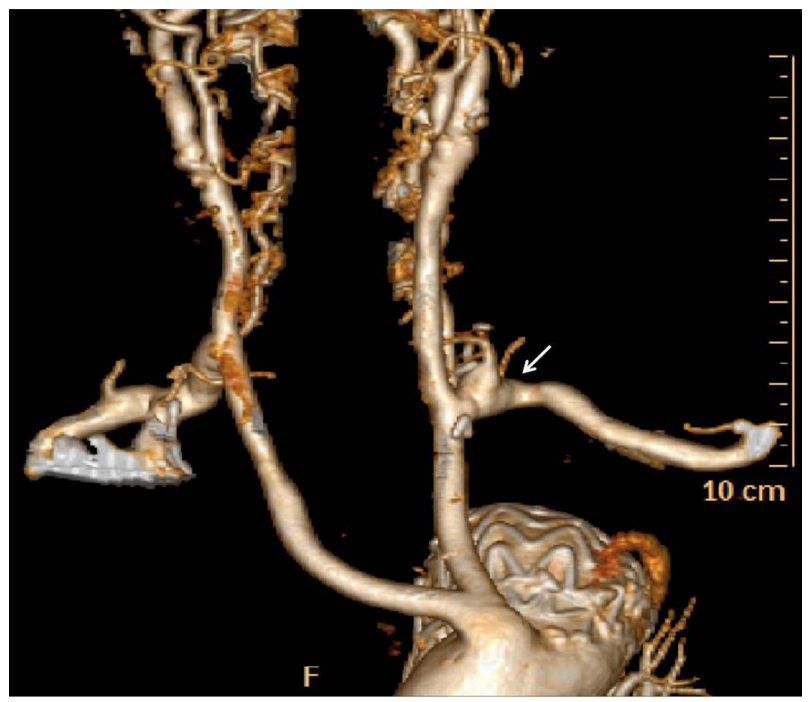

Figure 7 Arch debranching.

Notes: Creation of a proximal landing zone can be accomplished with arch debranching. In this case, a left subclavian to left common carotid transposition (arrow) was created in anticipation of a Zone 2 proximal landing zone for subsequent TEVAR. Others have described the addition of carotid-carotid bypass to allow Zone I proximal landing zone creation.

Abbreviation: TEVAR, thoracic endovascular aneurysm repair. et al in a patient with a Crawford type IV TAA in order to avoid the morbidities associated with an open repair. ${ }^{72}$

The choice of open verses hybrid approach is dependent on the patient's comorbidities, including the presence of severe COPD, the inability to tolerate a left thoracotomy, previous open thoracic operations, the presence of severe renal insufficiency, and cardiac impairment that would not tolerate proximal aortic clamping. ${ }^{73,74}$ By avoiding thoracotomy, extracorporeal perfusion, aortic cross-clamping, and single lung ventilation, the hybrid procedure has been suggested to have decreased mortality in high-risk patients. ${ }^{73,75}$ Other literature has suggested that the hybrid repair has no significant difference in outcomes when compared to open TAA repair. ${ }^{76-78}$

In approximately $20 \%$ of cases, the proximal seal zone can only be achieved by extending across the left subclavian artery origin. ${ }^{79}$ Current Society for Vascular Surgery guidelines recommend preoperative left subclavian revascularization in elective TEVAR and expectant management in acute settings, though this remains an area of debate. ${ }^{40}$ The presence of a left dominant vertebrobasilar system or the existence of a left internal mammary coronary artery bypass graft are strong indications to consider pre-emptive carotid-subclavian bypass or transposition in the elective intervention. Others advocate for reactive revascularization only if arm claudication or subclavian steal occurs after routine covering of the origin. It should also be noted that the left subclavian can be an important input to the collateral network feeding the anterior spinal artery, and as such, if other inputs are diseased or excluded, direct revascularization should be strongly considered. 
For the majority of hybrid TAA repairs, the proximity of the celiac, SMA, and renal arteries to one another will mandate visceral bypasses. Selective celiac artery coverage is feasible, but recent studies found a bowel ischemia rate of approximately $6 \%$ and an endoleak rate of approximately $16 \%{ }^{80,81}$ It is feasible to consider only mesenteric debranching in patients with pre-existing renal failure on dialysis. In general, the anatomy of the aneurysm will indicate the optimal origin for the retrograde bypass. For example, in a Crawford type I TAA, the native infrarenal aorta or a common iliac artery will provide a suitable graft origin. However, a Crawford type II or III TAA with contiguous dilation from the thoracic aorta throughout the common iliac vessels makes a hybrid repair challenging, and is best repaired with traditional open or total endovascular techniques.

The retrograde debranching is often performed using multi sidearm surgical grafts (Figure 8). Two of the limbs can be used to bypass to the right and left renal arteries, with the third limb being anastomosed to the SMA in an end-to-side fashion.
A jump graft is then created from this limb to the celiac axis. When creating the celiac artery anastomosis, the hepatic or splenic artery should be used because the exposure to the celiac bifurcation is difficult and leaves little room to ligate the main celiac trunk. It is necessary to ligate the origins of each debranched vessel to prevent a type II endoleak.

Staging of the hybrid repair is often necessary due to the long and technically demanding nature of the debranching procedure. This is especially true in the type II and III TAAs. The endovascular portion of the procedure should be performed as soon as the patient has recovered from the debranching procedure. It is advised that the staged procedures be performed during the same admission given that interval aneurysm rupture has been reported when patients are discharged after debranching. ${ }^{75,82}$ Some have advocated placing a conduit limb (10 mm diameter) into the subcutaneous tissues of the lower abdominal wall. At the time of the secondary endovascular procedure, a small lower abdominal incision is made and the conduit limb is delivered
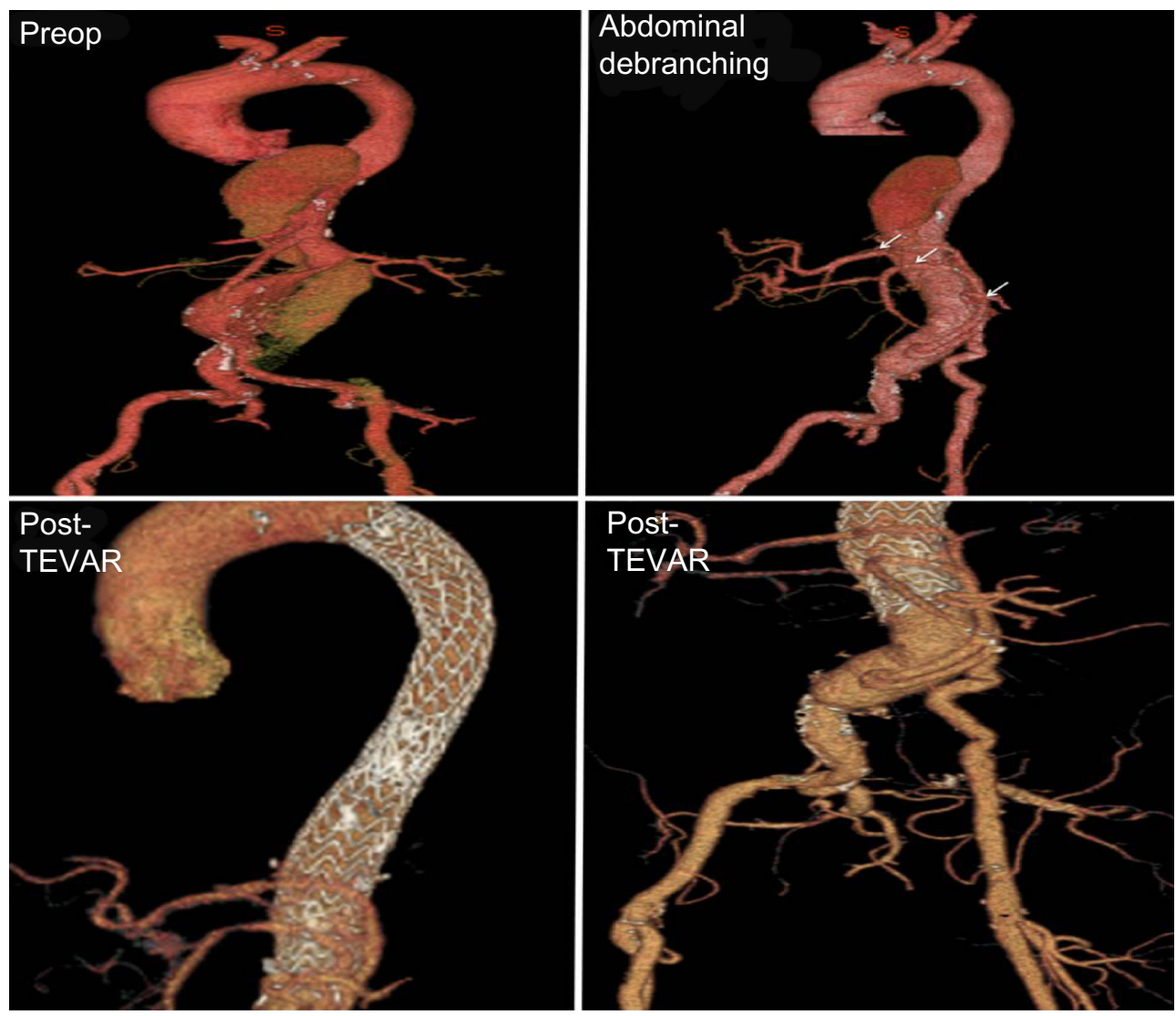

Figure 8 Multivisceral abdominal debranching.

Notes: Creation of a distal landing zone can be accomplished with abdominal debranching procedures. Celiac, SMA, and either or both renal arteries (arrows) can be debranched to facilitate TEVAR landing zones. Recent introduction of hybridized grafts has simplified this procedure. ${ }^{94}$ In addition, in those patients with poor access vessel diameter, a conduit limb can be tunneled into the anterior abdominal wall and left in place for future exposure, thrombectomy, and controlled access for later TEVAR introduction.

Abbreviations: Preop, preoperatively; SMA, superior mesenteric artery; TEVAR, thoracic endovascular aneurysm repair. 
and thrombectomized. It can then be used to cannulate and deploy the thoracic grafts.

There have been numerous case series evaluating the outcomes of hybrid TAA repairs. The Crawford type and emergency nature of these repairs must be taken into account when comparing outcome data. Overall, the 30-day mortality rates for the hybrid repair range from $0 \%-31 \%$. The morbidity ranges from $17 \%-56 \%$, with a paraplegia risk of $0 \%-10 \%$ and graft occlusion rate ranging from $0 \%-13 \% .{ }^{74,83-92}$ In one of the largest series to date $(n=107)$, Drinkwater et al had the highest number of type II $(n=45)$ and III $(n=32)$ TAA with a mortality rate of $15 \%$ and morbidity of $38 \%{ }^{87}$ Concordant with the complexity of these repairs, they reported a rate of spinal ischemia of $12.1 \%$ and a rate of permanent paraplegia of $8.4 \%$. Long-term dialysis was needed in $3.7 \%$ of patients, and $2.8 \%$ of the patients had an infarcted segment of bowel requiring resection. None of the cases in the Drinkwater series were emergent. ${ }^{87}$ The case series from Muehling's group out of Germany had 16 patients and reported the highest rate of emergency cases (38\%). They reported a mortality of $31 \%$ and morbidity of $44 \%$, with a paraplegia rate of $6 \% .{ }^{90}$ Quiñones-Baldrich's group reported a series of 20 patients with no mortalities at 30 days, a mean follow-up of 16.6 months, and an overall survival of $75 \%{ }^{84}$

The breadth of data indicates that the hybrid approach to TAA pathology is a reasonable option for high-risk patients. Patient selection and careful preoperative planning is crucial to the success of this approach.

\section{Summary}

As endovascular devices continue to mature, the breadth of patients that can be treated by total endovascular TAA repair continues to increase. In the absence of modular off-the-shelf devices, these custom-designed branched devices are limited in application to elective cases. However, as these technologies improve and operator learning curves advance, we can expect to treat an increasing population with total endovascular techniques. Hybrid options remain a viable alternative in those patients who require creation of a definitive landing zone.

\section{Disclosure}

DM received an honorarium from WL Gore. The other authors report no conflicts of interest in this work.

\section{References}

1. Stein L, Elefteriades J. Epidemiology and natural history of thoracoabdominal aortic aneurysms. In: Chiesa R, Melissano G, Zangrillo A, editors. Thoraco-Abdominal Aorta. Springer: Milan; 2011:25-32.
2. Clouse WD, Hallett JW Jr, Schaff HV, et al. Improved prognosis of thoracic aortic aneurysms: a population-based study. JAMA. 1998;280(22): 1926-1929.

3. Knepper J, Upchurch GR. A review of clinical trials and registries in descending thoracic aortic aneurysms. Semin Vasc Surg. 2010;23(3): $170-175$.

4. Crawford ES, Coselli JS. Thoracoabdominal aneurysm surgery. Semin Thorac Cardiovasc Surg. 1991;3(4):300-322.

5. Safi HJ, Miller CC 3rd. Spinal cord protection in descending thoracic and thoracoabdominal aortic repair. Ann Thorac Surg. 1999;67(6): 1937-1939; discussion 1953-1958.

6. Juvonen T, Ergin MA, Galla JD, et al. Prospective study of the natural history of thoracic aortic aneurysms. Ann Thorac Surg. 1997;63(6):1533-1545.

7. Frederick JR, Woo YJ. Thoracoabdominal aortic aneurysm. Ann Cardiothoracic Surg. 2012;1(3):277-285.

8. Kuzmik GA, Sang AX, Elefteriades JA. Natural history of thoracic aortic aneurysms. J Vasc Surg. 2012;56(2):565-571.

9. Etheredge SN, Yee J, Smith JV, Schonberger S, Goldman MJ Successful resection of a large aneurysm of the upper abdominal aorta and replacement with homograft. Surgery. 1955;38(6): 1071-1081.

10. Rob C. The surgery of the abdominal aorta and its major branches. Ann R Coll Surg Engl. 1955;17(5):307-318.

11. De Bakey ME, Cooley DA. Successful resection of aneurysm of thoracic aorta and replacement by graft. JAMA. 1953;152(8):673-676.

12. DeBakey ME, Crawford ES, Garrett HE, Beall AC, Howell JF. Surgical considerations in the treatment of aneurysms of the thoraco-abdominal aorta. Ann Surg. 1965;162(4):650-662.

13. Crawford ES. Thoraco-abdominal and abdominal aortic aneurysms involving renal, superior mesenteric, celiac arteries. Ann Surg. 1974; 179(5):763-772.

14. Bavaria JE, Appoo JJ, Makaroun MS, Verter J, Yu ZF, Mitchell RS; Gore TAG Investigators. Endovascular stent grafting versus open surgical repair of descending thoracic aortic aneurysms in low-risk patients: a multicenter comparative trial. J Thorac Cardiovasc Surg. 2007;133(2):369-377.

15. Parodi JC, Palmaz JC, Barone HD. Transfemoral intraluminal graft implantation for abdominal aortic aneurysms. Ann Vasc Surg. 1991;5(6):491-499.

16. Dake MD, Miller DC, Semba CP, Mitchell RS, Walker PJ, Liddell RP. Transluminal placement of endovascular stent-grafts for the treatment of descending thoracic aortic aneurysms. $N$ Engl $J$ Med. 1994;331(26):1729-1734.

17. Hughes GC, Barfield ME, Shah AA, et al. Staged total abdominal debranching and thoracic endovascular aortic repair for thoracoabdominal aneurysm. J Vasc Surg. 2012;56(3):621-629.

18. Moulakakis KG, Mylonas SN, Avgerinos E, et al. The chimney graft technique for preserving visceral vessels during endovascular treatment of aortic pathologies. J Vasc Surg. 2012;55(5):1497-1503.

19. Reilly LM, Rapp JH, Grenon SM, Hiramoto JS, Sobel J, Chuter TA. Efficacy and durability of endovascular thoracoabdominal aortic aneurysm repair using the caudally directed cuff technique. J Vasc Surg. 2012;56(1):53-63; discussion 63-64.

20. Chuter TA, Hiramoto JS, Park KH, Reilly LM. The transition from custom-made to standardized multibranched thoracoabdominal aortic stent grafts. J Vasc Surg. 2011;54(3):660-667; discussion 667-668.

21. Elefteriades JA, Botta DM Jr. Indications for the treatment of thoracic aortic aneurysms. Surg Clin North Am. 2009;89(4): $845-867$, ix.

22. Conrad MF, Crawford RS, Davison JK, Cambria RP. Thoracoabdominal aneurysm repair: a 20-year perspective. Ann Thorac Surg. 2007;83(2) S856-S861; discussion S890-S892.

23. Schepens MA, Heijmen RH, Ranschaert W, et al. Thoracoabdominal aortic aneurysm repair: results of conventional open surgery. Eur J Vasc Endovasc Surg. 2009;37(6):640-645. 
24. Huynh TT, van Eps RG, Miller CC, et al. Glomerular filtration rate is superior to serum creatinine for prediction of mortality after thoracoabdominal aortic surgery. J Vasc Surg. 2005;42(2):206-212.

25. Mell MW, Wynn MM, Reeder SB, Tefera G, Hoch JR, Acher CW. A new intercostal artery management strategy for thoracoabdominal aortic aneurysm repair. $J$ Surg Res. 2009;154(1):99-104.

26. Griepp RB, Griepp EB. Spinal cord perfusion and protection during descending thoracic and thoracoabdominal aortic surgery: the collateral network concept. Ann Thorac Surg. 2007;83(2):S865-S869; discussion S890-S892.

27. Griepp EB, Di Luozzo G, Schray D, Stefanovic A, Geisbüsch S, Griepp RB. The anatomy of the spinal cord collateral circulation. Ann Cardiothorac Surg. 2012;1(3):350-357.

28. Mastracci TM, Greenberg RK. Complex aortic disease: changes in perception, evaluation and management. JVasc Surg. 2008;48(Suppl 6): 17S-23S; discussion 23S.

29. Peterson BG, Eskandari MK, Gleason TG, Morasch MD. Utility of left subclavian artery revascularization in association with endoluminal repair of acute and chronic thoracic aortic pathology. J Vasc Surg. 2006;43(3):433-439.

30. Buth J, Harris PL, Hobo R, et al. Neurologic complications associated with endovascular repair of thoracic aortic pathology: Incidence and risk factors. a study from the European Collaborators on Stent/Graft Techniques for Aortic Aneurysm Repair (EUROSTAR) registry. J Vasc Surg. 2007;46(6):1103-1110; discussion 1110-1111.

31. Leurs LJ, Bell R, Degrieck Y, Thomas S, Hobo R, Lundbom J; EUROSTAR; UK Thoracic Endograft Registry collaborators. Endovascular treatment of thoracic aortic diseases: combined experience from the EUROSTAR and United Kingdom Thoracic Endograft registries. J Vasc Surg. 2004;40(4):670-679; discussion 679-680.

32. Cho JS, Haider SE, Makaroun MS. US multicenter trials of endoprostheses for the endovascular treatment of descending thoracic aneurysms. J Vasc Surg. 2006;43 Suppl A:12A-19A.

33. Makaroun MS, Dillavou ED, Kee ST, et al. Endovascular treatment of thoracic aortic aneurysms: results of the phase II multicenter trial of the GORE TAG thoracic endoprosthesis. J Vasc Surg. 2005; 41(1):1-9.

34. Matsumura JS, Cambria RP, Dake MD, Moore RD, Svensson LG, Snyder S; TX2 Clinical Trial Investigators. International controlled clinical trial of thoracic endovascular aneurysm repair with the Zenith TX2 endovascular graft: 1-year results. J Vasc Surg. 2008;47(2): 247-257; discussion 257

35. Demers P, Miller DC, Mitchell RS, et al. Midterm results of endovascular repair of descending thoracic aortic aneurysms with first-generation stent grafts. J Thorac Cardiovasc Surg. 2004;127(3):664-673.

36. Ellozy SH, Carroccio A, Minor M, et al. Challenges of endovascular tube graft repair of thoracic aortic aneurysm: midterm follow-up and lessons learned. J Vasc Surg. 2003;38(4):676-683.

37. Barrett BJ, Parfrey PS. Clinical practice. Preventing nephropathy induced by contrast medium. $N$ Engl J Med. 2006;354(4):379-386.

38. Laville M, Juillard L. Contrast-induced acute kidney injury: how should at-risk patients be identified and managed? J Nephrol. 2010; 23(4):387-398.

39. Bobadilla JL, Suwanabol PA, Reeder SB, Pozniak MA, Bley TA, Tefera G. Clinical implications of non-contrast-enhanced computed tomography for follow-up after endovascular abdominal aortic aneurysm repair. Ann Vasc Surg. 2013;27(8):1042-1048.

40. Matsumura JS, Rizvi AZ; Society for Vascular Surgery. Left subclavian artery revascularization: Society for Vascular Surgery Practice Guidelines. J Vasc Surg. 2010;52(Suppl 4):65S-70S.

41. Fairman RM, Criado F, Farber M, et al; VALOR Investigators. Pivotal results of the Medtronic Vascular Talent Thoracic Stent Graft System: the VALOR trial. J Vasc Surg. 2008;48(3):546-554.

42. Bobadilla JL, Wynn M, Tefera G, Acher CW. Reply: To PMID 23490292. J Vasc Surg. 2013;58(3):858-859.
43. Bobadilla JL, Wynn M, Tefera G, Acher CW. Low incidence of paraplegia after thoracic endovascular aneurysm repair with proactive spinal cord protective protocols. J Vasc Surg. 2013;57(6): $1537-1542$

44. Falkenberg M, Cronqvist J, Malina M. Early stent fracture and collapse of a Zenith TX2 thoracic stent graft used for traumatic aortic rupture. Vascular. 2011;19(5):287-290.

45. Nano G, Mazzaccaro D, Malacrida G, Occhiuto MT, Stegher S, Tealdi DG. Delayed endovascular treatment of descending aorta stent graft collapse in a patient treated for post- traumatic aortic rupture: a case report. J Cardiothorac Surg. 2011;6:76.

46. Shukla AJ, Jeyabalan G, Cho JS. Late collapse of a thoracic endoprosthesis. J Vasc Surg. 2011;53(3):798-801.

47. Jonker FH, Schlosser FJ, Geirsson A, Sumpio BE, Moll FL, Muhs BE. Endograft collapse after thoracic endovascular aortic repair. J Endovasc Ther. 2010;17(6):725-734.

48. Jonker FH, Mojibian H, Schlösser FJ, et al. The impact of hypovolaemic shock on the aortic diameter in a porcine model. Eur J Vasc Endovasc Surg. 2010;40(5):564-571.

49. Canaud L, Alric P, Desgranges P, Marzelle J, Marty-Ané C, Becquemin JP. Factors favoring stent-graft collapse after thoracic endovascular aortic repair. J Thorac Cardiovasc Surg. 2010;139(5):1153-1157.

50. Pasta S, Cho JS, Dur O, Pekkan K, Vorp DA. Computer modeling for the prediction of thoracic aortic stent graft collapse. J Vasc Surg. 2013;57(5):1353-1361.

51. Tadros RO, Lipsitz EC, Chaer RA, Faries PL, Marin ML, Cho JS. A multicenter experience of the management of collapsed thoracic endografts. J Vasc Surg. 2011;53(5):1217-1222.

52. Peterson BG, Matsumura JS. Internal endoconduit: an innovative technique to address unfavorable iliac artery anatomy encountered during thoracic endovascular aortic repair. J Vasc Surg. 2008;47(2): $441-445$.

53. White GH, Yu W, May J. Endoleak - a proposed new terminology to describe incomplete aneurysm exclusion by an endoluminal graft. J Endovasc Surg. 1996;3(1):124-125.

54. White GH, Yu W, May J, Chaufour X, Stephen MS. Endoleak as a complication of endoluminal grafting of abdominal aortic aneurysms: classification, incidence, diagnosis, and management. J Endovasc Surg. 1997;4(2):152-168.

55. Martin Z, Greenberg RK, Mastracci TM, Eagleton MJ, O'Callaghan A, Bena J. Late rescue of proximal endograft failure using fenestrated and branched devices. J Vasc Surg. 2014;59(6): $1479-1487$.

56. Troisi N, Donas KP, Austermann M, Tessarek J, Umscheid T, Torsello G. Secondary procedures after aortic aneurysm repair with fenestrated and branched endografts. J Endovasc Ther. 2011;18(2):146-153.

57. Austermann M, Donas KP, Panuccio G, Troisi N, Torsello G. Pararenal and thoracoabdominal aortic aneurysm repair with fenestrated and branched endografts: lessons learned and future directions. J Endovasc Ther. 2011;18(2):157-160.

58. Walsh SR, Tang TY, Sadat U, et al. Endovascular stenting versus open surgery for thoracic aortic disease: systematic review and meta-analysis of perioperative results. J Vasc Surg. 2008;47(5):1094-1098.

59. Stone DH, Brewster DC, Kwolek CJ, et al. Stent-graft versus opensurgical repair of the thoracic aorta: mid-term results. J Vasc Surg. 2006;44(6):1188-1197.

60. Jonker FH, Trimarchi S, Verhagen HJ, Moll FL, Sumpio BE, Muhs BE. Meta-analysis of open versus endovascular repair for ruptured descending thoracic aortic aneurysm. J Vasc Surg. 2010;51(4): 1026-1032, 1032.e1-1032.e2

61. Xenos ES, Minion DJ, Davenport DL, et al. Endovascular versus open repair for descending thoracic aortic rupture: institutional experience and meta-analysis. Eur J Cardiothorac Surg. 2009;35(2):282-286.

62. Greenberg R, Eagleton M, Mastracci T. Branched endografts for thoracoabdominal aneurysms. J Thorac Cardiovasc Surg. 2010; 140(Suppl 6):S171-S178. 
63. Guillou M, Bianchini A, Sobocinski J, et al. Endovascular treatment of thoracoabdominal aortic aneurysms. J Vasc Surg. 2012;56(1): 65-73.

64. Bisdas T, Donas KP, Bosiers M, Torsello G, Austermann M. Anatomical suitability of the T-branch stent-graft in patients with thoracoabdominal aortic aneurysms treated using custom-made multibranched endografts. J Endovasc Ther. 2013;20(5):672-677.

65. Bosiers MJ, Bisdas T, Donas KP, Torsello G, Austermann M. Early experience with the first commercially available off-the-shelf multibranched endograft (t-branch) in the treatment of thoracoabdominal aortic aneurysms. J Endovasc Ther. 2013;20(6):719-725.

66. Ricotta JJ, Tsilimparis N. Surgeon-modified fenestrated-branched stent grafts to treat emergently ruptured and symptomatic complex aortic aneurysms in high-risk patients. J Vasc Surg. 2012;56(6):1535-1542.

67. Oderich GS, Fatima J, Gloviczki P. Stent graft modification with mini-cuff reinforced fenestrations for urgent repair of thoracoabdominal aortic aneurysms. J Vasc Surg. 2011;54(5):1522-1526.

68. Tolenaar JL, van Keulen JW, Trimarchi S, Muhs BE, Moll FL, van Herwaarden JA. The chimney graft, a systematic review. Ann Vasc Surg. 2012;26(7):1030-1038.

69. Lobato AC, Camacho-Lobato L. Endovascular treatment of complex aortic aneurysms using the sandwich technique. J Endovasc Ther. 2012;19(6):691-706

70. Mestres G, Uribe JP, García-Madrid C, et al. The best conditions for parallel stenting during EVAR: an in vitro study. Eur J Vasc Endovasc Surg. 2012;44(5):468-473.

71. Minion D. Molded Parallel Endografts for Branch Vessel Preservation during Endovascular Aneurysm Repair in Challenging Anatomy. Int $J$ Angiol. 2012;21(2):81-84.

72. Quiñones-Baldrich WJ, Panetta TF, Vescera CL, Kashyap VS. Repair of type IV thoracoabdominal aneurysm with a combined endovascular and surgical approach. J Vasc Surg. 1999;30(3):555-560.

73. Zhou W, Reardon M, Peden EK, Lin PH, Lumsden AB. Hybrid approach to complex thoracic aortic aneurysms in high-risk patients: surgical challenges and clinical outcomes. J Vasc Surg. 2006;44(4):688-693.

74. Patel R, Conrad MF, Paruchuri V, Kwolek CJ, Chung TK, Cambria RP. Thoracoabdominal aneurysm repair: hybrid versus open repair. J Vasc Surg. 2009;50(1):15-22.

75. Böckler D, Kotelis D, Geisbüsch P, et al. Hybrid procedures for thoracoabdominal aortic aneurysms and chronic aortic dissections a single center experience in 28 patients. J Vasc Surg. 2008;47(4): 724-732.

76. Lee CW, Beaver TM, Klodell CT Jr, et al. Arch debranching versus elephant trunk procedures for hybrid repair of thoracic aortic pathologies. Ann Thorac Surg. 2011;91(2):465-471.

77. Chiesa R, Tshomba Y, Melissano G, et al. Hybrid approach to thoracoabdominal aortic aneurysms in patients with prior aortic surgery. J Vasc Surg. 2007;45(6):1128-1135.

78. Milewski RK, Szeto WY, Pochettino A, Moser GW, Moeller P, Bavaria JE. Have hybrid procedures replaced open aortic arch reconstruction in high-risk patients? A comparative study of elective open arch debranching with endovascular stent graft placement and conventional elective open total and distal aortic arch reconstruction. J Thorac Cardiovasc Surg. 2010;140(3):590-597.
79. Cheng D, Martin J, Shennib H, et al. Endovascular aortic repair versus open surgical repair for descending thoracic aortic disease a systematic review and meta-analysis of comparative studies. J Am Coll Cardiol. 2010;55(10):986-1001.

80. Mehta M, Darling RC, Taggert JB, et al. Outcomes of planned celiac artery coverage during TEVAR. J Vasc Surg. 2010;52(5): 1153-1158.

81. Rao AS, Rhee RY. Coverage of the celiac artery during TEVAR: is it ever appropriate? Semin Vasc Surg. 2009;22(3):152-158.

82. Lee WA, Brown MP, Martin TD, Seeger JM, Huber TS. Early results after staged hybrid repair of thoracoabdominal aortic aneurysms. J Am Coll Surg. 2007;205(3):420-431.

83. van de Mortel RH, Vahl AC, Balm R, et al. Collective experience with hybrid procedures for suprarenal and thoracoabdominal aneurysms. Vascular. 2008;16(3):140-146.

84. Quiñones-Baldrich W, Jimenez JC, DeRubertis B, Moore WS. Combined endovascular and surgical approach (CESA) to thoracoabdominal aortic pathology: A 10-year experience. JVasc Surg. 2009;49(5):1125-1134.

85. Chiesa R, Tshomba Y, Melissano G, Logaldo D. Is hybrid procedure the best treatment option for thoraco-abdominal aortic aneurysm? Eur J Vasc Endovasc Surg. 2009;38(1):26-34.

86. Donas KP, Lachat M, Rancic Z, et al. Early and midterm outcome of a novel technique to simplify the hybrid procedures in the treatment of thoracoabdominal and pararenal aortic aneurysms. J Vasc Surg. 2009;50(6):1280-1284.

87. Drinkwater SL, Böckler D, Eckstein H, et al. The visceral hybrid repair of thoraco-abdominal aortic aneurysms - a collaborative approach. Eur J Vasc Endovasc Surg. 2009;38(5):578-585.

88. Biasi L, Ali T, Loosemore T, Morgan R, Loftus I, Thompson M. Hybrid repair of complex thoracoabdominal aortic aneurysms using applied endovascular strategies combined with visceral and renal revascularization. J Thorac Cardiovasc Surg. 2009;138(6): 1331-1338.

89. Wolf O, Eckstein HH. Combined open and endovascular treatment of thoracoabdominal aneurysms and secondary expanding aortic dissections: early and mid-term results from a single-center series. Ann Vasc Surg. 2010;24(2):167-177.

90. Muehling BM, Bischoff G, Schelzig H, Sunder-Plassmann L, Orend KH. Hybrid procedures for complex thoracoabdominal aortic aneurysms: early results and secondary interventions. Vasc Endovascular Surg. 2010;44(2):110-115.

91. Kabbani LS, Criado E, Upchurch GR Jr, et al. Hybrid repair of aortic aneurysms involving the visceral and renal vessels. Ann Vasc Surg. 2010;24(2):219-224.

92. Ham SW, Chong T, Moos J, et al. Arch and visceral/renal debranching combined with endovascular repair for thoracic and thoracoabdominal aortic aneurysms. JVasc Surg. 2011;54(1):30-40; discussion 40-41.

93. Adams JD, Garcia LM, Kern JA. Endovascular repair of the thoracic aorta. Surg Clin North Am. 2009;89(4):895-912, ix.

94. Levack MM, Bavaria JE, Gorman RC, Gorman JH, Ryan LP. Rapid aortic arch debranching using the Gore hybrid vascular graft. Ann Thorac Surg. 2013;95(6):e163-e165.

Vascular Health and Risk Management

\section{Publish your work in this journal}

Vascular Health and Risk Management is an international, peerreviewed journal of therapeutics and risk management, focusing on concise rapid reporting of clinical studies on the processes involved in the maintenance of vascular health; the monitoring, prevention and treatment of vascular disease and its sequelae; and the involvement of

metabolic disorders, particularly diabetes. This journal is indexed on PubMed Central and MedLine. The manuscript management system is completely online and includes a very quick and fair peer-review system, which is all easy to use. Visit http://www.dovepress.com/ testimonials.php to read real quotes from published authors. 